\title{
Emotional Labour and Employee Performance Appraisal: The Missing Link in Some Hotels in South East Nigeria
}

\author{
Igbojekwe, Poly A. Ph.D \\ Department of Hospitality and Tourism Management, Imo State University, Owerri, Nigeria
}

\begin{abstract}
The main objective of this study was to determine if emotional labour has become a criterion in performance appraisal, job description, selection, and training schemes in the hotel industry in Nigeria. Our main assumption was that majority of hotel organizations have not built emotional labour into their human resources management schemes. Data were gathered by the use of structured questionnaires designed in Likert format, and interviews. The focus group was managers of the selected hotels. Analyses revealed that majority of the hotels have not built emotional labour into their human resources schemes particularly in the 1, 2, and 3-star hotels. It was observed that service employees of 1, 2, and 3-star hotels have not been adequately trained to perform emotional labour; a critical factor in quality service delivery. Managers of 1,2, and 3-star hotels have not given serious thought to emotional labour as a critical factor in quality service delivery. The study revealed that suitability of an individual's characteristics is not being considered as a criterion for selection and performance appraisal for service employees. The implication of this is that, person-job-fit is not seriously considered. It was observed that there has been a disconnect between required emotional competency, its recognition, evaluation and training. Based on the findings of this study, it is concluded that selection, training, job description and performance appraisal instruments in use in hotels in Nigeria are inadequate. Human resource implications of the findings in this study are presented. It is recommended that hotel organizations should re-design and plan the emotional content and context of their human resources practices to reflect the emotional demands of frontline jobs in the hotel industry and the crucial role emotional labour plays during service encounters.
\end{abstract}

Keywords: Emotional labour; employee selection; job description; performance appraisal; person-job-fit;

\section{Background of study}

Jobs in the hospitality sector are particularly vulnerable to emotional labour demands as they are characterized by an underlying expectation for employees to display a positive disposition, even when faced with situations that normally elicit negative emotional reactions such as being inpatient, over-demanding or irate customer (Hoel and Einarsen, 2003; Pizam, 2004). Hospitality service environment is so challenging because some of the customers arrive at the establishments with negative emotions while attempting to run away from unpleasant situations encountered at their homes, workplaces, society etc. Many a time, these customers use hotel workers as inanimate objects (scapegoat) for venting their frustration.

The skill with which emotional labour is performed impacts on perception of service quality (Provis et al, 2003; Parasuraman et al, 1988). The handling of difficult and unruly customer requires the active suppression and/or masking of one's own emotion while simultaneously expressing an alternate emotion. The service worker is expected to be upbeat and positive in the face of criticism and complaints (Provis et al, 2003). He is expected to wear cheerful face, beaming "professional smile" no matter the situation.

In the hospitality industry, face-to-face transactions have the greatest power to make an impression on the guest. Here the customer/guest can undertake a full assessment of people, their manner, appearance and general behaviour. Therefore, the personal contact that takes place must be of superior quality. The service employees need to be able to put themselves in the other person's shoes, in other words, they should be able to empathize with the customers; put up friendly and cheerful face at all times in a way that is not going to be seen as just an act, but seen to be or at least appear sincere (Power, 1992). The service employee must deliberately involve his/her feelings in the situation.

In an environment of heightened customer expectations and stiff competition, hotel organizations must emphasis on guest's total experience. Customer experience includes interactions with an organization's people, processes or systems; feelings or emotional responses generated by the interaction (Thompson, 2007). Customer experience is the most important factor in gaining customer loyalty (Brandi, 2006). Service experience is therefore, an essential element in the transaction. If the server is grumpy or heavy-handed, the guest most likely would be unhappy.

Given the crucial role emotional labour plays in service excellence and the negative effects associated with its performance, it is imperative that suitable service employees are selected and trained to cope with the demands associated with the performance of such labour, so that their well-being is not affected and subsequent interactions with customers are not tarnished. Researchers have also revealed that the performance of emotional labour is largely unrecognized (Karabanov, 1999; Provis et al, 2003). However, at intuitive level the managers and hotel front-line workers recognize that their jobs touch one's feelings (emotions), and they know the 
challenges associated with the performance of such a job. Emotional labour being an invisible labour is unrecognized. Hence, it is not built into job descriptions, performance appraisals, and reward system (Guy et al, 2008).

It has been observed that during selection, testing of applicants for emotion work skill, a critical factor in the performance of emotional labour is not seriously considered; a practice that can result to hiring of individuals who lack the requisite emotional competence. Rather, more attention is given to technical and cognitive skills required to perform observable tasks. Conflict situation which occurs during the working hours between service delivery employees and guests may result in a future loss of business for the hotel due to emotional failure on the part of the service delivery employees. Camillo and Connolly (2008) report that among the key findings of their study was that internal factors such as over-confidence and emotional unfitness lead to the failure of independent restaurants. This means that relying solely on observable task characteristics is insufficient. Attending only to cognitive skill, the employer sees only one dimension of the applicants' performance. Compensating cognitive skills but not emotive skills depresses the earnings of those performing emotive work (Guy et al, 2008). Standard human resources procedures that can stand the test of time include competency-based job descriptions based on objective analysis that evaluate job applicant's ability to perform requisite tasks; performance appraisals that objectively evaluate overall worker performance; and compensation schedules that are linked to knowledge, skills, and abilities (KSAs) that are observable or quantifiable (Guy et al, 2008). Competency-based job description contrasts with the traditional job description in terms of job duties and responsibilities. The competency-based job description focuses more on how the worker meets the job objectives or actually accomplishes the work. Unfortunately it has also been observed that most job descriptions and performance appraisals are not competency-based.

One obvious implication of not including emotive skill in job description is that job difficulties and distastes are concealed from job applicants, and employees are not trained to deal with them. The result is that when employees find out what the job really involves, they are likely to behave in manners that lead to loss of goodwill and adverse effect on organizational performance (Mullins, 2005). Job description ought to paint a realistic picture of the jobs associated with emotional labour. In some situations the employees leave the organization a short period after being employed. Staff is more likely to stay with an organization for a reasonable time and provide a satisfactory standard of work if the job description paints a clear and realistic picture of the job and their personal attributes and qualities match closely those required for successful performance of the job and/or potential future job (Mullins, 2005). Another implication of not including emotive skill in job description is that service workers are not appraised nor rewarded for the performance of emotional labour

Every organization wants to have employees who have the necessary knowledge, skill and ability to perform their assigned roles. In the hospitality industry there is a growing awareness of the need to carefully select employees since customer relations' skills, particularly of front-line staff, are vital. Companies should recognize the need to carefully screen applicants, with more consideration given to personality and other relevant characteristics of potential employees in recognition of the emotional demands of those front-line jobs (Berger and Ghei, 1995; Kuemmler and Kleiner, 1996). Hence, the importance of systematic approach to selection and training cannot be over emphasized. It is widely acknowledged that the delivery of quality service commences with the selection of suitable employees and provision of appropriate training (Provis et al, 2003; Guy et al, 2008; Tucker, 2010). Thus, it is important that organizations select with the aim of achieving the best personjob-fit. Wing, Yuanyuan and Zigguang (2010) have found positive correlation between emotional labour, person-job fit and job satisfaction. Research evidence suggests that person-job fit leads to job satisfaction and higher service interaction quality. A useful way to accomplish this task may be to use personality tests that measure affectivity traits and other personality characteristics that are relevant in customer service jobs. For example, applicants who demonstrate a high level of positive affectivity would be considered a good fit for service-oriented occupation.

Anderson (2002) and Ashforth and Humphrey, (1993); Sutton, (1991) argue that it is probable that working on emotional labour from a selection perspective may be more valuable than attempts at socialization and training since selecting employees on the basis of their affectivity and general tendency to experience certain emotion may lead to a better fit between employees' expressive behaviours and work-role requirement while selection based on personality would generate greater benefit to the industry.

It was against this backdrop that this study was conducted to obtain the views of hotel managers and the extent to which hotel organizations have included emotion work skill in their job descriptions and performance appraisals.

\section{Statement of the Problem}

In an ideal situation a human resource system maintains effective linkage between job description, employee manual, and performance appraisal and compensation schemes. In the hotel industry, job description ought to 
highlight the emotional demands of the job of frontline employees; also emotional labour ought to be part of the formal performance evaluation as well as part of the training topic. Researches in emotional labour suggest that individual characteristics will be highly predictive of whether an employee performs emotional labour as part of his work role (Guy et al, 2008; Chu, 2002). These individual characteristics are treated as antecedents of emotional labour (Chu, 2002). Some individuals are energized by emotional encounters, while others find them exhausting. Whereas some are skilled at emotional suppression, others excel at developing rapport and emotional engagement. Unfortunately, most job description and performance appraisal instruments fail to highlight emotional labour demands thereby missing out the individual competencies required to do the job; a practice that may have resulted to low professionalism and high job turnover in the hotel industry in Nigeria.

\section{Objective of the study}

The main objective of the study was to determine if emotional labour has become a criterion in performance appraisal, selection, and training. Our main assumption is that majority of the organizations have not built emotional labour into their human resources management schemes.

\section{Conceptual Framework}

In this sub-section, the following concepts are presented: performance appraisal, employee selection, training, job analysis, job description, job specification, and the person-job-fit theory.

\section{Performance Appraisal}

The performance appraisal/evaluation activities enable to determine whether the employees' performance is in accordance with established objectives and it is primarily based on the appraisal of employees' work results and activity (behaviour), also competence (skills, abilities and characteristics). In the modern management, performance appraisal is viewed in the broader context of performance management, whereas precision of measurement and accuracy of ratings is accompanied by social and motivational aspects of the appraisal process (Fletcher, 2001). Alongside with task performance, which covers job-specific behaviours and employee's core responsibilities, in the appraisal process more attention has been devoted to non-job specific behaviours, like cooperation, dedication, enthusiasm and persistence. These aspects form contextual performance, because of increasing organizational and task complexities are becoming more and more important (Boyd and Kyle, 2004). Employees' compensation is a process of rewarding employees with monetary and non-monetary benefits according to the value of their work, thus, compensating them for their efforts.

Performance appraisal is a systematic process that seeks to evaluate employees' performance and helps in identifying employee's potential for further growth and advancement within the organization's career ladder. The basic aim of performance appraisal system is to monitor employee performance, boost employee motivation that will in turn improve company morale and is a useful tool for understanding and assessing employee skill potential. Mostly supervisors are the immediate source of judging and evaluating the performance of their subordinates, however in some recent methods of performance appraisal like $360^{\circ}$ feedback employee is being evaluated by everyone that comes in contact with him, be it a supervisor, colleague, customers, peer, subordinate managers, team members, suppliers and vendors (Turk, 2005).

This type is different from other traditional method of performance appraisal as in this information about employee is gathered from all possible sources to sketch full picture of employee performance i.e. a full assessment of employee from multiple sources. On the contrary, subordinate (appraisees) are also recognizing the importance of performance appraisals, since this tool of performance management affects their rewards and paves the way for further developmental opportunities like trainings, promotions, transfers, salary increases bonuses etc.

Similarly data gathered through performance appraisal also known as performance evaluation can also be used as a tool for providing Employees Feedback about their performance. Performance evaluation is a systematic process that is done on a periodic basis i.e. annually or bi-annually in some organizations, the basic purpose is to assess individual employee's job performance and productivity according to certain pre-established criteria and organizational objectives.

Performance appraisal takes into account the past performance of the employees and focuses on the improvement of the future performance of the employees. Other purposes of conducting performance appraisals/evaluation are: Developmental and Evaluative Purposes. Developmental purpose is used to identify the weak areas of employee's performance. The gathered data is then used to provide trainings and development opportunities to the employee. On the other hand evaluative purpose helps organizations /evaluators in informing employees about their performance and further in rewarding excellent performance and to punish poor performance.

In addition, Fletcher (2001) opined that performance appraisal as a means by which organizations develop competency, improve employee motivation and achieve equitable allocation of resources. In essence, 
performance appraisal achieves multiple purposes from measurement to motivation and resource allocation. As noted by Cleveland, Murphy, and Williams (1989), performance appraisal systems can be used to motivate employees through remuneration, promotions, retrenchment, and the improvement of skills, competence and expertise. Moreover, Seidan, and Sowa. (2011) believe that the ultimate objective of any evaluation procedure is aligning individual goals and objectives with organizational objectives and priorities while individual performance should be reflected in how they contribute to organizational growth and development. According to Bassey, Esu and Inyang (2009), performance appraisal system is a means of investigating employee achievement over a certain period of time for achieving organizational goals. Consequently, performance appraisal is a means of knowledge sharing among subordinates and superiors to adequately measure the progress of the employee which will aid in making strategic human resource decisions.

The effectiveness of an appraisal system is determined by the performance standards. Hence standards must be established according to individual job description which should be tied to organizational goals and objectives. Furthermore, these standards should be a written document which will make it legally binding and objective. Failure to align performance standards with organizational goals and objectives leads to misunderstandings, poor morale, and lack of job satisfaction, ineffectiveness, and confusion (Daley, 2002; Condrey 2012).

Knowledge, skills and abilities, work ethics, personality traits or characteristics and results all can be used to assess performance (Milkovich and Boudreau, 1994). Even though, knowledge, skills and abilities are difficult and costly to measure due to the fact that they are inherent in an individual not specific to the job itself but they signify the minimum requirement needed for optimum job performance. Behaviours are mostly used in the public sector due to the nature of the organization which encourages and incorporates teamwork. Ultimately, organizational culture, organizational climate and nature of the job influence the direction of the appraisal procedure (Murphy and Cleveland, 1995; Daley, 2002; Condrey, 1994 \& 2012).

In summary the purposes of performance appraisal in work organizations are:

1. Administrative - promotion, dismissal, organizational planning

2. Motivational - self appraisal and acts as an incentive to hard work

3. Developmental - identify training needs

4. Performance Improvement - through MBO, participative goal setting and other work planning processes.

Job Description is defined by Dressler (2008) as a list of a job's duties, responsibilities, reporting relationships, working conditions, and supervisory responsibilities; it is a list of what the job entails. It is a product of job analysis. Job description information is used to write a job specification; this lists the human requirements, requisite education/knowledge, personality, abilities and skills required to perform the job satisfactorily. Job specification is used primarily by employing officer in the selection and placement of the right person for the specific position. Job specification when used appropriately helps organizations to achieve person-job-fit. It is another product of job analysis.

Job Analysis is the procedure for determining the duties and skill requirements of a job and the kind of person who should be hired for it (Dressler (2008). This definition of traditional job analysis contrasts with the newer approach to job analysis which is the competency-based job analysis. The competency-based job analysis means describing the job in terms of the measurable, observable, behavioural competencies (knowledge, skills, and/or behaviours) that an employee doing that job must exhibit to do the job well. This approach emphasizes what the employee must be capable of doing, rather than on a list of duties he must perform; it is a worker focused while traditional job analysis is job focused-duties and responsibilities

\section{Person-Job-Fit Theory}

The term human resource management (HMR) as emerging concept emphasizes the integration of the both strategies and operational activities to achieve the desired results. HRM practices- recruitment and selection, training and development, performance evaluation and reward system are essential to achieve this result. Human Resource Management is the most critical function of any organization as it deals with the most complicated problems - the people problems (Mullins, 2005), especially when the organizations are operating in highly competitive and uncertain environments. Strategic human resource management (SHRM) lays emphasis on developing and implementing policies and strategies in order to get the desired output. Therefore, person-job fit analysis and strategic HRM are inter-related. Establishing a person-job-environment fit is the basic function of SHRM.

Many years ago, organizations were concerned with personality primarily because they wanted to match individuals to specific jobs. That concern still exists. But, in recent years, interest has expanded to include the individual-organization-fit. Today's managers are less interested in an applicant's ability to perform a specific job than with his or her flexibility to meet changing situations. Thus, person-job fit is the concept that recognizes the requirements of the job moderated by the relationship between possession of the personality 
characteristic and job performance or in order words matching the job requirements with personality characteristics (Edwards, 1991; Lawrence, 2004). The theory is based on the notion of fit between an individual's personality characteristics and his or her occupational environment. The theory proposes that satisfaction and the propensity to leave a job depend on the degree to which individuals successfully match their personalities to an occupational environment. The P-J fit identifies job satisfaction, low job stress, motivation, performance, attendance, and retention as outcomes that are positively affected by P-J fit. When P-J fit is assessed as the match between what an employee wants and receives from performing job, it is correlated with improved job satisfaction, adjustment, and organizational commitment, as well as reduced intentions to quit. Additional benefits for task performance have been demonstrated when the definition of PJ fit is expanded to include match between abilities and their job demands (Cable and Edwards 2004; Saks and Ashforth, 2002; Erdogan and Bauer, 2005).

Strategic Human Resource Management is all about making strategies and policies to place right person at the right place and at the right time to get the maximum out of an employee. In other way, it is concerned about optimal utilization of human resources. In various studies, person-job fit has been found to be related to productivity and commitment (Rousseau \& Mc Lean Parks, 1992), job performance (Greenberg, 2002) and having positive effects on performance, job satisfaction, and reduction in job stress, motivation, attendance and retention (Edwards, 1991). Interestingly Kristoff et al. (2005) found that when person-job fit and personorganisation fit were tested on job performance, the relationship tend to have a modest correlations which contradicts with the findings by Li and Hung (2010) where person-job fit found to be highly correlated with job performance.

It has been proposed by Rafaeli and Sutton (1987) that there might be some situations in which performing emotional labour can bring positive consequences. They suggest that when expressed feelings are congruent with experienced emotions, employees are then experiencing emotional harmony which is an indication of good fit between person and job requirement. Their idea corresponds with person-job-fit theory. The person-job-fit theory further strengthens the above argument and therefore suggests that when individuals' characteristics are congruent with the job requirements, job satisfaction increases. In contrast, when there is lack of congruence between individuals' characteristics and requirements, job satisfaction drops and stress increases. Individuals then seek opportunities to leave the situation.

Based on person-job-fit theory, one's personality or characteristics can fit job requirements of particular emotional displays, then it is assumed that an individual will experience more emotional harmony" than emotional dissonance (the gap between one's felt emotions and expressed emotions). For example, if one's personality is more cheerful and upbeat, then this individual will probably find it effortless to be friendly or enthusiastic when interacting with customers (Chu, 2004). It is very likely that this individual will find enjoyment in emotional labour because his or her self-concept can be realized in the work context. In the above scenario, this individual is in a situation where it is possible to experience the positive consequences of emotional labour. On the other hand, if there is a lack of fit between one's personality and job requirements, then the individual will probably experience more negative consequences of emotional labour including stress and job dissatisfaction.

\section{Selection and Training}

Every organization wants to have employees who have the necessary knowledge, skill and ability to perform their assigned roles. In the hospitality industry there is a growing awareness of the need to carefully select employees since customer relations' skills, particularly of front-line staff, are vital. Companies should recognize the need to carefully screen applicants, with more consideration given to personality and other relevant characteristics of potential employees in recognition of the emotional demands of those front-line jobs (Berger and Ghei, 1995; Kuemmler and Kleiner, 1996). Hence, the importance of systematic approach to selection and training cannot be over emphasized. It is widely acknowledged that the delivery of quality service commences with the selection of suitable employees and provision of appropriate training (Provis et al, 2003; Guy et al, 2008; Tucker, 2010). Thus, it is important that organizations select with the aim of achieving the best personjob-fit. Wing, Yuanyuan and Zigguang (2010) have found positive correlation between emotional labour, person-job fit and job satisfaction. Research evidence suggests that person-job fit leads to job satisfaction and higher service interaction quality. A useful way to accomplish this task may be to use personality tests that measure affectivity traits and other personality characteristics that are relevant in customer service jobs. For example, applicants who demonstrate a high level of positive affectivity would be considered a good fit for service-oriented occupation.

Anderson (2002) and Ashforth and Humphrey, (1993); Sutton, (1991) argue that it is probable that working on emotional labour from a selection perspective may be more valuable than attempts at socialization and training since selecting employees on the basis of their affectivity and general tendency to experience certain emotion may lead to a better fit between employees' expressive behaviours and work-role requirement while 
selection based on personality would generate greater benefit to the industry. Training in the needed skills is still needed. Researchers have found that training directly influences service-oriented behaviours of staff. Training also indirectly affects the intention of front-line staff to leave the organization; it increases job satisfaction, which in turn has an impact on affective commitment.

Fostering emotional competence through training might also help employees to better understand the customers' perspective as well as to better understand organizational values, and to thus enhance interaction quality with their customers (Cossette and Hess2009). Criminologists have evaluated the effectiveness of emotion management training and have generally found a positive correlation between training and officer performance (Guy et al, 2008; Davis, Mateu-Gelabert, and Miller (2005). Training sessions and workshops organized to discuss and exercise emotion management practices and protocols that set forth rules of emotional display and expression would serve to legitimize and institutionalize this work (Guy, et al, 2008). Guy et al, (2008) report findings from their study that new employees were trained in the technical skills of the job but not in the emotion work skills. Only 58 percent of workers they surveyed responded that their job training prepared them to do their jobs well.

Performance of emotional labour using surface acting as strategy is stressful because of the discrepancy between felt and displayed emotions (for example, feeling angry but having to fake happiness as part of the work role) leads to emotional dissonance. Thus, training people to deep act may be a valuable organizational tool. People could use deep acting strategies such as trained imagination to "psyche themselves up" before entering their work role, to ensure that their emotional displays are genuine (Kiely, 2008). Employees could be taught how to reappraise situations thereby acquire the skills that will assist them transform emotions and handle difficult situations without becoming overwhelmed. It is widely acknowledged that trained workers make fewer mistakes than untrained ones .Better training may bring about a lower incidence of burnout. Guy et al, (2008) found that people who report that their training prepared them well for the job-related challenges that they face did not score as high on burnout as those who reported that their training was inadequate.

This section has demonstrated the importance of training. For organization to succeed in delivering goods and services of sufficient quality that can provide customer satisfaction, proper customer culture must be adopted. According to Macanachie (2005), Morgan and Sayer (1985) stated that 'workers of particular qualities are not just born waiting to be hired; they have to be hired and trained. Less skilled workers make inappropriate responses or responses that fail to facilitate the interaction.

\section{Research Methodology}

In this section the methods used in the study were presented. It deals with the following: research design, description of the study population, sample size determination, data collection instrument, and its administration, test of validity and reliability, and method of data analysis. This study is a descriptive research; hence, a survey method was adopted. Descriptive data are typically collected through a questionnaire, an interview, observation (Gay, 1976) and recorded events and documents.

\section{Population of the study and Sampling Procedure}

The population for the study comprised of managers of hotel establishments in the South-Eastern zone Nigeria. Hotels of one (1) to five (5) star classification were used in this study. A total of thirty one (31) hotels were selected for the study. The total population was 223. A non-probability sampling method was adopted in choosing the establishments for the study. In this study stratified sampling was used to determine individual company's sample size. By applying the stratified method, and using the Bouley"s (1964) population allocation formula given by Okeke (1995) we determined sample size for each hotel. Random sampling method was used to select respondents from each establishment. Due to the heterogeneous nature of the study population, the Taro Yamane's formula given by Alugbuo (2005) was used to determine the sample size from the hotels selected for the study. Applying this formula, sample size for managers was 143.

\section{Data Collection Instrument and Administration}

The primary data in this study were collected through structured questionnaire and oral interview. In this study, the Likert-type scale was used. According to Gay, 1976; Kerlinger, 1973), a likert scale asks an individual to respond to a series of statements by indicating whether he or she strongly agrees (SA), agree (A), undecided (U), disagree (D), or strongly disagree (SD) with the statement. Each response is associated with a point value and an individual's score is determined by summing the point values. For each point value, 4, 3, 2, 1 and 0 were assigned to strongly agree (SA), Agree (A), disagree (D), strongly disagree (SD) and not applicable (NA) respectively to positive responses. For negative statements the point values were reversed, strongly agree was assigned one (1). Likert scaling is a bipolar scaling method, measuring either positive or negative response to a statement (Hall, 2010). When a four-point scale is used by eliminating the middle option of "undecided or neither agree or disagree", it is referred to as a forced choice method. In this study the forced choice method was 
adopted to minimize central tendency error.

\section{Designing the Research Instrument}

In this study some questions were adapted from developed, pre-validated and reliable scales in addition to those generated by conducting pilot studies and extensive literature search. Attitude statements for the study were generated through in-depth interviews and discussions with the operators of the industry (focus group) and lecturers in the field of hospitality. Validity and reliability tests were conducted for the modified scales. The questionnaire was designed following procedure described by Hall (2010). The questionnaire is presented in the Appendix - B. The Cronbach's alpha coefficient for internal consistency was used to determine reliability of the research instrument. Procedures described by Gliem and Gliem (2003) and Onunkwo (2002) were adopted. For the sub-scales measuring the use of emotional labour as a criterion for performance appraisal, selection and training, the alpha values were 0.86 and 0.82 .

\section{Data Analysis Techniques}

Descriptive statistics for the study variables were determined. This involved calculating mean scores, mode, standard deviation and simple percentages for each attitude statement and sub-scales. Data were also presented in frequency distribution tables.

\section{Research Results}

Out of one hundred and forty three (143) copies of questionnaire distributed, one hundred and ten (110) were properly completed and returned by the respondents. Responses from the participants were tabulated and presented in tables. Frequency distribution tables are presented in Appendix B. In Table 1A descriptive statistics with which to find out if emotional labour has been built into performance appraisal scheme are presented.

*Table 1A

** Table 2A

\begin{tabular}{|l|l|l|l|l|l|l|l|l|l|}
\hline Star & $(n)$ & $\overline{\text { Mean }}$ & $(\mathbf{S D})$ & Mode & Star & $(\mathrm{n})$ & Meān & (SD) & Mode \\
\hline 1 & 20 & .56 & .61 & 0 & 1 & 20 & .80 & .63 & 1 \\
\hline 2 & 20 & .58 & .56 & 1 & 2 & 20 & .87 & .70 & 1 \\
\hline 3 & 24 & 1.12 & .70 & 1 & 3 & 24 & 1.1 & .70 & 1 \\
\hline 4 & 24 & 1.61 & .76 & 2 & 4 & 24 & 1.4 & .70 & 1 \\
\hline 5 & 22 & 2.02 & .57 & 2 & 5 & 22 & 2.3 & .56 & 2 \\
\hline \multicolumn{7}{|c|}{ Source: Survey data 2014 }
\end{tabular}

*Table 1A Descriptive statistics for emotional labour as a criterion in performance appraisal **Table 2A. Descriptive statistics for selection and training of employees on how to perform emotional labour.

The mean is used to describe the extent to which the organizations apply emotional labour as a criterion in performance appraisal of service (customer-contact) employees. Any mean below 2.5 indicates that hotel organizations do not apply emotional labour as a criterion in performance appraisal. The overall mean was 1.08 $(\mathrm{SD}=0.57)$ meaning that the organizations do not apply emotional labour as a criterion in performance appraisal. None of the hotel classes scored a mean of 2.5 and above. The highest mode for response options was 2 indicating disagreement to its importance and use as a criterion in performance appraisal. In the 5-star hotels it has limited application. For the 1-star hotels, the mean of $0.56(\mathrm{SD}=0.60)$ means that emotional labour has no place in their performance appraisal scheme.

Data presented in Table $1 \mathrm{~b}$ (in the appendix) are used to indicate the proportion of respondents (managers) who agreed or disagreed to emotional labour being used as criterion in performance appraisal. Above data indicate that managers in 1 to 4 star hotels do not agree that EL can be used as criterion in performance appraisal. While managers in 5 star hotels agree that it has limited application. For the 1-star hotel class, close to $50 \%$ responded not applicable, indicating that emotional labour has no place in performance appraisal. Only 5\% of all the respondents agreed that emotional labour is used as a criterion in performance appraisal. Looking at the overall picture, strongly disagree has the highest frequency (38.3\%).

In Table 2A, data with which to find out if emotional labour has formed part of selection and training topic were presented. The mean is used here to describe the extent to which the hotel managers have recognized the importance of selecting employees with emotive skill and training them in emotional labour management 
strategies. Mean scores below 2.5 indicate that hotel organizations do not train their employees as to how to perform emotional labour, in other words, in selection and training, EL has not formed part of their training topic. Only the 5-star class scored mean of $2.36(\mathrm{SD}=0.56)$ which is above expected mean of 2.5 , however, its mode for response options was 2. The mode for response options for 1 to 3-star hotel classes was one (1). The same situations apply to selection of employees. In terms of selection, technical skill receives more attention than emotive skill.

Data presented in Table 2B (in the appendix) describe the proportion of managers who agreed or disagreed that during selection and training emotional labour is an important topic. Above data indicate that it is only in the five star hotels that training in emotional labour handling is carried out but to a limited level. For 13 -star classes no respondent responded agree. For the 1-star class, strongly disagree has the highest frequency $(56.3 \%)$ followed by not applicable $(32 \%)$

\section{Discussion of findings and their Implications}

In this sub-section, findings of the study are discussed and their implications are presented under the following headings: performance appraisal, and selection and training.

\section{Performance Appraisal Programme}

In this study, performance of emotional labour was found to be unrecognized. In the course of this study, during the interview session some managers explained that they do not know any terminology, word or phrase to explain emotional labour as a phenomenon; hence, it is not built into job description and performance appraisal schedules. The implications are that service employees are not appraised for performance of emotional labour and their emotional contribution towards the achievement of organizational goals are also not appreciated. The job of a service employee requires high level of emotive skill, yet, he is not explicitly evaluated based on his emotive skill capabilities and his job description does not cover emotional labour. This is a serious human resources problem for the hotel industry in Nigeria. Performance appraisal for service employees based more on cognitive and technical skills which neglect emotive skill is inadequate. Such appraisal instruments cannot stand the test of time. Since emotive skill requirements of emotional labour are not contained in appraisal instruments, they are likely not to be covered by job descriptions. A standard job description ought to paint a clear and realistic picture of the requirements of a job and is used to match the personal attributes of employees and potential employees during recruitment and selection exercises. Job descriptions for customer-contact employees currently in use in hotel organizations in Nigeria are inaccurate by not highlighting the emotional demands of their jobs. This practice creates room for hiring of individuals who are emotionally unfit to handle frontline jobs. This is also a serious human capital issue that deserves serious attention.

\section{Employee Selection}

For hotel organizations to succeed in today's dynamic business world, they must take proactive approaches, one of which is by selecting individuals who possess the necessary characteristics/personality for performance of emotional labour to achieve a good person-job-fit. It is clear that attitudes and behaviours of employees during service encounters are a great factor in customer perceptions of service quality. Rendering of quality service and management of emotions of both customers and service employees commence with selection. It is easier and cheaper to train individuals with the appropriate characteristics for a particular job than to train those who lack the appropriate characteristics. Selecting the right candidate for the job of service provider in the hotel industry is crucial for both employee and organizational performance. As observed from the current study, hotel organizations pay more attention to technical and cognitive skills during selection. Therefore, there is the need for hotel organizations to re-examine and redesign their human resources practices and incorporate the concept of emotional labour into their staff selection, training and compensation policies. Hotels can use various selection tests and techniques such as aptitude and personality

Training of Employees It has been widely acknowledged that the delivery of quality service commences with the selection of suitable candidate and provision of appropriate training. Findings in this study revealed that little formal attention is paid to the training of employees for performance of emotional labour. There is little evidence that training programmes take account of the difficulties in performing emotional labour and coping strategies that may be necessary and useful. Considering the deleterious effect of emotional labour on employees' wellbeing, the importance of coping strategies cannot be over emphasized. Coping strategies play a major role in individuals physical and psychological well-being when they are confronted with stressful life event such as expressing emotions not felt (surface acting). Training enhances workers skills. Trained employees are a great asset to organizations. It is also widely acknowledged that sound human resources management practices in respect of selection and training of service employees will contribute to the effective performance of emotional labour and customers' perception of service quality. Training programmes designed to address issues concerning emotional labour in hotel organizations where customers are "always right" and sense of servitude associated 
with this type of jobs, training of employees on how to cope with such situations is crucial. Training will strengthen workers' emotive skill so that they will serve the customers better and with sincere hospitality and consistency. Considering the fact that during service interaction ("moment of truth"), the manager would have no opportunity to shade away or re-call negative attitudes and behaviours of service employees. We therefore recommend that hotel organizations should take proactive measures by proper selection and giving appropriate training to service employees; a training that considers the difficulties of emotional labour.

\section{Recommendations}

The findings of this study have human resource (HR) implications. Most of the organizations are still using traditional job description, and performance appraisal which focus on tasks. We recommend that hotel organizations should: adopt the competency-based approaches which focus on the demonstratable characteristics of the individual, put person-job-fit into consideration during selection, re-design and build emotional labour into their human resources schemes to reflect the emotional demands of frontline jobs in the hotel industry.

\section{REFERENCES}

Anderson, B, Provis, C., and Chappel, S. (2002), The Recognition and Management of Emotional Labour in the Tourism Industry. Research Report series, $C R C$, Website www.crctourism.com.au

Ashforth, B.E. and Humphrey, R.H. (1993), Emotional labour in service roles: The Influence of Identity. Academy of Management Review, Vol. 18(1).

.Boyd, N. M., Kyle, K. (2004), Expanding the View of Performance Appraisal by Introducing Social Justice Concerns, Administrative Theory \& Praxis

Berger, F. and Ghel, A. (1995). Employment Test: A Facet of Hospitality Hiring. Cornell Hotel and Restaurant Administration Quarterly, 36.

Brandi, J. (2006), Customer Service Training Programme for Relationship Management. http://www.customercoach.com.

Carmello, A. (2003). The Relationship Between Emotional Labour and Work attitudes, behaviours and Outcomes: An Examination among senior managers. Journal of Managerial Psychology. Vol. 18.

Chu, K.H. (2002). The Effects of Emotional Labour on Employee work outcome. Virginia Polytechnic Institute and State University, U.S.A.

Cossette, M. and Hess, U. (2009), Role of Organizational Factors on Emotional Labour Strategies. ASAC-2009. University of Quebec at Montreal.

Davis, R.C., Mateu-Gelabert, P, and Miller, J. (2005), Can effective Policing Also be Respectful? Police Quarterly, Vol. 8.

Dressler, G.(2008). Human Resource Management, $7^{\text {th }}$ Edition, New Jersey. Pearson Prentice Hall.

Gay, L.R. (1996). Educational Research: Competencies for Analysis and Application. Ohio, U.S.A., Charles E. Merril Publishing Inc.

Gay, L.R. (1996). Educational Researcy: Competencies for Analysis and Application. Ohio, U.S.A., Charles E. Merril Publishing Inc.

Guy, M.E., Newman, M.A. and Mastracci, S.H. (2008), Emotional Labour: Putting the service in public service. New York, M.E. Sharpe, Lc.

Hall, S. (2010). How to use the Likert Scale in Statistical Analysis. Ehow.com;

Hoschschild, A.R. (1983), The Managed Heart Communication of Human Feeeling Berkeley of California Press. http://www.ehow.com.

Hoel H. Einarsen, S. (2003). A Review of Violence and Stress in the Hotel, Catering and Tourism Industry. ILO. Geneva. www.ILO.org/public.

Karabanow, J. (1999), When caring is not enough: Emotional Labour and Youth workers. Social Service Review, 73. www.jstor.org.

Keily, S. and Savatos, P. (2008), Emotional Labour: A Significant interpersonal Stressor. University of Western Australia, In Psych.

Kerlinger, F.N. (1973). Foundations of Behavioural Research. $2^{\text {nd }}$ edition. New York. Holt Rinehart and Winston Inc.

Kristof-Brown, A. (2007). Person-job fit. In S. Rogelberg (Ed.), Encyclopedia of industrial and organizational psychology. (pp. 619-621). Thousand Oaks, CA: SAGE Publications, Inc. doi: http://dx.doi.org. (Accessed $20^{\text {th }}$ November, 2014).

Lawrence, A.D. (2004). Screening for Person-Job fit: Incremental validity of a congruence approach to assessment. (Doctoral dissertation). Retrieved from ProQuest Dissertations and Theses database. (AAT 3123386).

Mullins, L.J. (2005), Management and Organizational Behaviour. $7^{\text {th }}$ edition, Edinburgh Gate, England. Prentice Hall and Pearson Educational Limited. 
Parasuraman, A., Zeithaml, V. and Berry, L. (1988), SERVQUAL: A Multiple item scale for Measuring Consumer Perceptions of Service Quality. Journal of Retailing, Vol. 64. www.proserv.nu.

Okeke, A.O. (1995). Foundation Statistics for Business Decisions. Enugu. High Mega System LTD.

Onunkwo, G.I.N. (2002). Fundamentals of Educational Measurement and Evaluation. Owerri, Cape Publishers International Limited.

Pizman, A. (2004), Are Hospitality Employees Equipped to hide their feelings? (editorial). International Journal of Hospitality Management, 23.

Power, T. (1992), Introduction to Hospitality Management. New York. McMillan Press.

Provis, C., Chappel, S.J. and Anderson, B.A. (2003), The Selection and Training of Workers in the Tourism and Hospitality Industries for the Performance of Emotional Labour. Journal of Hospitality and Tourism Management. Jan, 2003.

Rafaeli, A., and Sulton, R.I., (1989). The expression of emotion in organization Life. Resources and organizational Behaviour, Vol. 11(1).

Rousseau, D.M., \& McLean Parks, J. (1992). The contracts of individuals and organisations. Research in Organisational Behaviour, 15, 1-47

Saks, A.M., \& Ashforth, B.E. (2002). Is job search related to employment quality? It all depends on fit. Journal of Applied Psychology, 87 (2), 646-54

Seldin, P. (1993). The use and abuse of student ratings of instruction', The Chronicle of Higher Education, 21 July, p. A-40. CA.

Thompson, B. (2007). Customer Experience Management: The value of "moment of truth". www.rightnow.com or CRMGURU.com.

Türk. K. (2005). The Study of Performance Appraisal And Compensation In Estonian Public And Private Universities University Of Tartu, Estonia

Tucker, E.D. (2010). Emotional management trainings effect on emotional labour and employee job performance. School of Hotel and Restaurant Administration Oklahoma state University.

Wing, L. Yuanyuan, H. and Ziguang, C. (2010). Why need someone who fits to serve?: Person-job-fit, customer desirability, and emotional labour. $7^{\text {th }}$ International Conference on emotion and Work life. Canada, Aug. 2010
APPENDIX A. Key Questions of the Administered Questionnaire
Our Performance appraisal criteria for customer service employees include:
1. emotion regulation skill. 2.ability to deal with happy customers only
3. ability to hide inappropriate emotions 4. ability to comply with approved display rules
5. Ability to experience emotions he must display. 6. Customer orientation behaviours
7. his personality disposition 8 . ability to resolve customer-service related problems.

Our formalized training for customer- service employees include how to:

1. express emotions not felt 2 . cope with stress 3 reduce tension caused by

job difficulties 4. match inner feelings with facial expressions 5. reappraise situations

6. act genuinely at work at all times 7. resolve customer related problems independently. 8. During selection of customer-service employees, our primary concern is technical knowhow. 9 During selection of customerservice employees, our primary concern is his personality.

APPENDIX B. Descriptive statistics Table

Table 1B. Emotional Labour as a Criterion in Performance Appraisal

\begin{tabular}{|l|l|l|l|l|l|l|}
\hline Hotel & Sample & & & & & \\
\hline Grade & Size & $\mathbf{0}$ & $\mathbf{1}$ & $\mathbf{2}$ & $\mathbf{3}$ & $\mathbf{4}$ \\
\hline Star & $(\mathbf{n})$ & NA & SD & D & A & SA \\
\hline 1 & 20 & $81(50.68)$ & $69(43.12 \%)$ & $10(6.3 \%)$ & 0 & 0 \\
\hline 2 & 20 & $73(45.63)$ & $81(50.63 \%)$ & $6(3.8 \%)$ & 0 & 0 \\
\hline 3 & 24 & $35(18.22)$ & $102(53.13 \%)$ & $52(27 \%)$ & $3(1.6 \%)$ & 0 \\
\hline 4 & 24 & $15(7.8)$ & $64(33.33 \%)$ & $95(49.5 \%)$ & $18(9.4 \%)$ & 0 \\
\hline 5 & 22 & $2(1.14)$ & $21(12 \%)$ & $125(71 \%)$ & $28(16 \%)$ & 0 \\
\hline Overall & 110 & $206(23.4)$ & $337(38.3 \%)$ & $288(32.73 \%)$ & $49(5.6 \%)$ & 0 \\
\hline
\end{tabular}

Source: survey data 2014 
ISSN (Paper) 2312-5187 ISSN (Online) 2312-5179 An International Peer-reviewed Journal

Table 2B Selection, and Training of Employees on how to Perform Emotional Labour

\begin{tabular}{|l|l|l|l|l|l|l|}
\hline Hotel & Sample & & & & & \\
\hline Grade & Size & $\mathbf{0}$ & $\mathbf{1}$ & $\mathbf{2}$ & $\mathbf{3}$ & $\mathbf{4}$ \\
\hline Star & $(\mathbf{n})$ & NA & SD & D & A & SA \\
\hline 1 & 20 & $51(32 \%)$ & $90(56.3 \%)$ & $19(12 \%)$ & 0 & 0 \\
\hline 2 & 20 & $51(32 \%)$ & $79(49.4 \%)$ & $30(18.8 \%)$ & 0 & 0 \\
\hline 3 & 24 & $39(20.3 \%)$ & $95(49.5 \%)$ & $58(30.2 \%)$ & 0 & 0 \\
\hline 4 & 24 & $17(9.0 \%)$ & $84(44.6 \%)$ & $81(43.3 \%)$ & $6(3.2 \%)$ & 0 \\
\hline 5 & 22 & 0 & $28(18.2 \%)$ & $106(69 \%)$ & $20(13 \%)$ & 0 \\
\hline Overall & 110 & $158(18.56)$ & $376(44.13 \%)$ & $292(34.3 \%)$ & $26(3.1 \%)$ & 0 \\
\hline
\end{tabular}

$$
\text { Source: survey data } 2014
$$

KEY: $\mathrm{O}=\mathrm{NA}=$ Not applicable (i.e. El has no place at all.....)

$1=\mathrm{SD}=$ Strongly disagree (not important at all)

$2=\mathrm{D}=$ Disagree (not important)

$3=\mathrm{A}=$ Agree (Important)

$4=$ SA $=$ Strongly Agree (very important) 